\title{
A Pragmatic Framework for the Cognitive Study of Documentary
}

Catalin Brylla and Mette Kramer

\begin{abstract}
Traditionally, there has been little intersection between cognitive film theory and documentary studies. This article initially outlines the main reasons for this lacuna, but it also highlights the few existing exceptions. While these remain too embryonic to initiate a large, overarching, and evolving discourse, they constitute seminal landmarks and stepping stones for the future of cognitive documentary studies, which, as we argue, needs to be a pragmatic endeavor. Based on this premise, we propose a research framework consisting of four areas of interest: the mediation of realities; character engagement; emotion and embodied experience; and documentary practice. This framework takes into account intratextual and extratextual aspects in relation to documentary production and reception, as well as potential social impacts.
\end{abstract}


On the one hand ... despite the seamless conjunctions of cinematic fiction and documented fact, we usually know the difference between the two.... On the other hand ... insofar as all cinematic objects are equivalently composed of images and sounds be they fictional or factual, there is no necessary difference between the two at all. (Sobchack 2004: 261)

The apparent paradox that Vivian Sobchack points out reflects the ambivalence found in scholarly approaches to documentary ${ }^{1}$ — an ambivalence that results from the large spectrum of documentary forms and corresponding spectatorial receptions. The conceptualization and production of documentary is far more prone to a bricolage approach that intermixes different aesthetics, authorial interventions, viewing contexts, and modes of spectatorial address, whereas fiction films adhere in general to a relatively more homogeneous set of conventions, usually with the primary aim of constructing a coherent diegesis. Correspondingly, the study of documentary studies, too, necessitates a bricolage approach, combining paradigms, models, and methods from different disciplines. Furthermore, the institutional and sociocultural functions that frame documentary's production and reception often overlap, blurring the boundaries between, for example, reportage, reality TV, ethnographic film, docudrama, educational film, promotional video, and avant-garde film. From a metatheoretical perspective, this article suggests a pragmatic research framework concerned with the multitude of social, cultural, historical, and psychological factors informing the conception and reception of documentary. This framework, which is grounded and based on cognitive principles but is expandable across other disciplines, aims to examine the range of documentary forms and implications within a wider sphere than that of traditional film scholarship or filmmaking. It points to potentially fruitful avenues of research into documentary using a cognitive perspective, and encourages scholars to adopt a more deliberately pragmatic approach thereto.

"Documentary" is a multilayered concept that has undergone several modifications since its inception. These can be traced from John Grierson's early definition of documentary as the “creative treatment of actuality” (1966: 147-148) to John Corner’s coinage of the term 
"post-documentary," which he describes as the "result of the widespread dispersal (and, in part, perhaps dissipation) of documentarist energies and appeals across a much larger area of audio-visual culture” (2000: 688). Corner, however, is prudent to mention that the prefix "post” does not suggest the collapse of documentary into postmodern doubt; rather, it refers to the move away from a rhetorical and didactic form of communication to an emphasis on cultural and commercial popularity, as seen in the expanded range of formats of realist-factual entertainment (688). This represents a significant shift from the style of documentary prevalent in Grierson's era, which was more confined in terms of form, production, and spectatorship to the current heterogeneous array of popular and democratic audiovisual nonfiction genres consumed (but also to a large degree produced) by a mass society.

Studying documentary from a cognitive studies perspective yields opportunities to account for this heterogeneous array of formats and functions, since living in a massmediated culture, in which reality is filtered through the prism of factual media, Western audiences' emotional and cognitive comprehension of the world is, to a significant extent, informed and consolidated by documentary. A cognitive approach can illuminate the conception, production, exhibition, and reception of documentaries, exploring intratextuality (in which filmmakers employ narrative and aesthetic strategies to achieve particular audience responses and effects) and extratextuality (whereby filmmaking practices and sociocultural traditions negotiate the indexical link between representations and their real-life counterparts). The interplay between these levels renders documentaries potentially more significant than fiction films in terms of our perception of and interaction with the real world, appreciably contributing to how we construct our social, cultural, and individual identities. After all, the two unique features of documentary spectatorship (as compared to fiction) are first an awareness of the real-life implications of the viewed content (Eitzen 2007) and second the assumption that documentaries make factual assertions, unless there are concrete reasons to believe otherwise (Plantinga 2013: 44).

The article will first discuss existing intersections of cognitive theory and 
documentary studies, outlining the main reasons why these two fields have not yet significantly converged. The few scholarly exceptions to this lacuna are acknowledged and highlighted as significant landmarks for establishing a pragmatic, interdisciplinary discourse. This is followed by the proposition of a research framework consisting of four areas of interest: the mediation of realities; character engagement; emotion and embodied experience; and documentary practice. The framework takes into account the intratextual and extratextual context of documentary production and reception, as well as its social impact. The aim is not to prescribe a comprehensive theoretical model, but to encourage the reconfiguration and expansion of existing frameworks (in both cognitive and documentary film studies) to address the wide spectrum of documentary, including classical as well as contemporary forms that deviate from the doctrine of factuality, such as essay films, performative documentaries, docudramas, and animated documentaries. Hence, instead of providing a detailed case study for the application of the entire framework, the article offers some short examples of films that could be expanded on in future research.

\section{The Intersection of Cognitive Theory and Documentary Studies}

Historically, the convergence between documentary and cognitive film studies has been inhibited by a somewhat ossified division, which is the result of a number of assumptions held by scholars in both fields. For their part, documentary scholars generally deem cognitive models too limited: they lament that by using scientific paradigms based on the concept of a universal, hardwired audience reception cognitive models have neglected sociocultural and historical contexts (e.g., Smaill 2010: 8), and have also limited the levels of spectatorship to knowledge acquisition through rationalist inquiry, such as narrative comprehension (e.g., Renov 2004: 149). At first glance, the existing body of work in cognitive film studies appears to justify the first assertion because, apart from occasional acknowledgments of social, cultural, political, and historical contexts in theoretical texts (e.g., Bondebjerg 2017; Peterson

1996; Plantinga 2009), rigorous applied studies are-at best—few and far between. ${ }^{2}$ There is 
also little evidence to dispel the second assumption because, although cognitive film scholars have begun to eschew strictly rationalist modes of inquiry in favor of analytical models that take affective and subjective viewer experience into account, this development has had little exposure or acknowledgment outside the discipline itself. The result is that noncognitive film scholars hold relatively fossilized views about the perceived stagnant and conservative nature of cognitive theory.

Meanwhile, cognitive film scholars have largely privileged the analysis of fiction film over that of documentary, a tendency that is mainly attributable to four factors. First, cognitive film theory developed in the 1990s as (arguably) a theoretical alternative to the influential Marxist, psychoanalytic, semiotic and poststructuralist Screen tradition (Bordwell and Carroll 1996; Plantinga and Smith 1999; Tan 1996), and since the Screen scholars focused mainly on fiction, it was logical that the cognitivists would also pursue their research in this area.

Second, despite Corner's suggestion that documentary is becoming increasingly mainstream, audience appreciation of documentary is still perceived to pale into insignificance beside the overwhelming popularity of mainstream fiction. Given that one of the aims of cognitivists is to analyze prototypical narratives in order to understand our preoccupation with, and the pleasure we derive from, watching mainstream films (Shimamura 2013: 4), it is perhaps not surprising that documentary is thought to offer little scope for the study of mainstream audiences. However, this assumption fails to take into account the fact that, although cinema documentaries have a still-limited (albeit growing) popularity, documentary content on television (especially reality TV, infotainment, and newscasts) and online (in the form of compilation films, mashups, and audiovisual memes) is becoming increasingly popular and ubiquitous.

A third factor that skews cognitive research toward the study of fiction is the continued acceptance of the classic definition of documentary as rhetorical or didactic, a 
“discourse of sobriety” (Nichols 1991: 3) that is incapable of eliciting the same high-level emotions and character engagement as fiction narratives. However, although this description may apply to documentaries such as wildlife films or current affairs, it does not hold true for documentary forms, such as character-driven observational documentaries, that are more closely aligned with fiction.

The final factor is the contrasting perception that documentaries use the same aesthetics and produce the same cognitive responses as fiction films (see, e.g., Shimamura 2013: 21) and that most cognitive models will apply equally well to both. This assumption, however, only appears plausible in light of bottom-up approaches analyzing sensory and lowlevel cognitive responses (as these may indeed be identical for fiction and nonfiction film), but it excludes essential top-down considerations, such as the spectator's evaluation of whether and to what degree the content is fiction or nonfiction. These last two contradictory perspectives, one based on the opposition and the other on the correspondence between fiction and nonfiction films, reflect Sobchack's (2004) aforementioned reference to the paradox of documentary. This is arguably symptomatic of its relatively amorphous nature, which encompasses the diverse spectrum of forms and functions involved in the evocation of different types of “documentary relationship” with viewers. Thus, although the perspectives outlined above may apply to particular cases, they are far less easy to defend as general propositions.

Yet, despite these barriers, there have been tentative intersections between documentary and cognitive theory. For example, documentary studies occasionally make explicit reference to spectatorial cognition in relation to narrative and aesthetics (e.g., Austin 2007; Corner 2008; Richardson and Corner 1986) and the representation of space (e.g., Chanan 2010). However, the majority of studies exhibit only faint traces of cognitive considerations, as when textual analyses merely draw inferences about audience reception (e.g., Nichols 1994; Renov 1993; Winston 2008) or categorize documentaries as particular “types” (e.g., Nichols 2001; Ward 2005). Meanwhile, some documentary scholars have 
adopted ethnographic (e.g., MacDougall 1998, 2006; Pink 2009) and psychoanalytic (e.g., Cowie 2011; Renov 2004; Piotrowska 2013) perspectives in order to address general questions about the role that emotions and embodied experiences play in documentary production and reception. Nevertheless, for the most part these texts do not rely on psychological ideas or models that originate in empirical studies or in theoretical discourses in the cognitive and affective sciences.

On the other hand, a handful of cognitive film scholars have engaged in the study of documentary, highlighting in particular its specificity when compared with fiction (e.g., Carroll 2003; Currie 1999; Eitzen 2007; Plantinga 2005; Ponech 1999), its different modes of narrative address (e.g., Odin 1989; Plantinga 1997; G. Smith 2007), and its audience reception (e.g., Bondebjerg 1994; Eitzen 1995; Plantinga 2013). But although these are seminal texts, they remain largely embryonic_-isolated bridgeheads between the two fields. The intersection between cognitive film theory and documentary studies still awaits the development of an overarching discourse that builds on, adapts, expands, or revises these pioneering studies.

Such a discourse would need to go beyond the much-rehearsed ontological question of what documentary is and semiotic arguments about the indexical relationship between representation and represented. Cognitive discourses can of course make an important contribution to the exploration of these areas; however, focusing solely on these subjects risks limiting the potential for cognitive approaches to create a new theoretical and empirical agenda. In addition, a generalizing discourse about the nature of documentary is highly problematic, as it potentially reduces the study of the vastly diverse documentary forms, institutions, platforms, and audiences that have emerged over the last few decades to the production of what C. Wright Mills (2000) calls “grand theories” that proffer abstract, deterministic, universally applicable deductions. Carl Plantinga (2005) underlines this point by using the example of two recurrent documentary models found in scholarly work, “documentary as indexical record” and “documentary as authorial assertion,” to illustrate his 
argument that the models’ abstract generalizations fail the applied test of real case studies.

The study of documentary therefore calls for a pragmatic approach, in which even ontological and indexical issues could prove useful if embedded in the investigation of a very particular body of films or a specific case study.

\section{A Pragmatic Approach}

Pragmatism, in combination with Maurice Merleau-Ponty’s and Martin Heidegger's phenomenological ideas, is a major paradigm in the relatively recent strand of embodied cognition studies (see, e.g., Madzia and Jung 2016: 3-5; Wang 2015) that focus on the "4EA" (Embodied, Embedded, Enacted, Extended, Affective) properties of cognition. Mark Johnson (2006: 371) attributes this pragmatic turn in particular to John Dewey's argument that human experience is an amalgamation of biological and cultural matrices, and thus needs to be studied through a variety of disciplines, including neuroscience, linguistics, developmental psychology, cognitive psychology, anthropology, and sociology. ${ }^{3}$

Our application of such a pragmatic approach to documentary analysis follows in the footsteps of three scholars, Ib Bondebjerg, Dirk Eitzen, and Carl Plantinga, whose pragmatist and phenomenological ideas have two common denominators: the premise that the evaluation of "reality" is located in the perceiver rather than in metaphysical discourse and the presupposition that documentary spectatorship is shaped by the degree of filmic mediation relative to particular viewing contexts. Eitzen (1995: 92) provides the basis for the premise with his description of documentary as a "mode of reception" that needs to be studied not as a kind of “film text” but as a kind of “reading.” This reception-driven approach largely bypasses questions about the actual definition of documentary (98). It also places the locus of ascertaining the degree of factuality and the degree of fictionality in the viewer, resonating with Sobchack’s (2004: 261) phenomenological idea that the difference between documentary and fiction ultimately represents the difference experienced in the viewer's consciousness when actively engaging with and evaluating cinematic objects. Eitzen also concludes that 
“[d]ocumentaries are presumed to be truthful, even though considerations about the veracity of particular [authorial] assertions may play little role in how viewers actually make sense of them” (1995: 88). The study of documentary spectatorship therefore needs to go beyond indexical concerns about objectivity, factuality, and truth claims to analyze the spectator's cognitive and affective perception of the documentary's “mediated” reality, in which the degree of mediation is as variable as the spectator's awareness of it.

In a similar vein, Bondebjerg (1994: 82-83) argues that the pragmatic approach requires the mapping of textual, social, and cultural elements in relation to psychological frameworks as well as institutional practices. This mapping relates not only to the study of audiences, but also to the study of filmmakers and their practices. He considers documentary reception as an intersubjective mediation of reality involving a "communicative contract" between film/filmmaker and audience, which is shaped by filmmaking practices and the audience’s schematic configurations of mental frameworks based on their perceptual and embodied capacities, as well as their past experiences (66-67). Plantinga (2013: 43-46), too, stresses the importance of a contextual, grounded, and reception-focused line of inquiry, arguing that when confronted with truth claims (for example, in social-activist documentaries), audiences understand that documentaries are structured rhetorical discourses and evaluate the film's indexical veracity using textual cues, the reputation of the filmmaker or institution, critics’ reviews, and common-sense psychology. Eitzen’s, Bondebjerg's, and Plantinga’s pragmatic ideas integrate dimensions of documentary spectatorship based on intratextual, extratextual, and intertextual considerations, thus enabling the researcher to survey the large spectrum of documentary forms and functions. Interestingly, although not a cognitive discourse per se, Nichols's (2001) pivotal taxonomy of “documentary modes” is very much attuned to this methodology. These modes (poetic, observational, interactive, expository, performative, and reflexive) may not be sufficiently comprehensive to account for more contemporary documentary forms, such as animated documentaries, and only allude to cognitive and emotional processes without actually using related theoretical models, but they 
still constitute prototypical categories that are pertinent to the examination of the narrative, aesthetic, sociocultural, and intertextual schemas ingrained in spectators and filmmakers. In addition, they are interdisciplinary, in that they are loosely based on theories adapted from fields such as documentary studies, cultural studies, anthropology, philosophy, and film practice itself.

The point is that a pragmatic-cognitive study of documentary requires the building of bridges between the natural sciences, social sciences, and humanities, as well as between film theory and practice. Bondebjerg (2015) argues that such an interdisciplinary collaboration is essential for an understanding of the way human cognition and emotion operate in culture and society; biology (particularly neurobiology) is necessarily embedded in that understanding. In essence, he reiterates Charles Percy Snow’s classic call for a dialogue between the (natural and social) sciences and the humanities (Bondebjerg 2015: 2) —a partnership that could prove highly efficient in triangulating the analysis of documentary spectatorship and authorship. ${ }^{4}$

Although mostly applied to fiction films, contemporary cognitive film studies feature this kind of dialogue between what Ted Nannicelli and Paul Taberham (2014) identify as two key strands within the discipline: a newer strand, informed by the methodology of the natural sciences, that seeks to generate empirical data based on the experience of film texts, and a more traditional strand, shaped by theoretical frameworks, that tests hypotheses through models adopted from modern psychology and underpinned by methods used in the humanities.

\section{A Research Framework in Lieu of a Spectatorship Model}

Cognitive approaches to film traditionally conceive schematic models that attempt to describe sensory, emotional, or cognitive processes in the viewer. For instance, Per Persson's (2003: 39) film reception model (Figure 1) outlines three basic elements of film viewing: “meaning” is generated in relation to the film text (“discourse”) and to spectator dispositions that are shaped by the current film's viewing, by past film viewings, and by “everyday life” (i.e., real 
life). Persson uses the word “meaning” in its broadest sense to denote the coherent mental interaction of the film with the spectator (2003: 19ff.), which he develops into a more intricate model of multiple levels of meanings, starting at a nonrepresentational level (lowlevel cognition of, for instance, shapes and colors) and finishing at an interpretational level (high-level cognition of, for instance, social themes) (2003: 26-37).

\section{Figure 1}

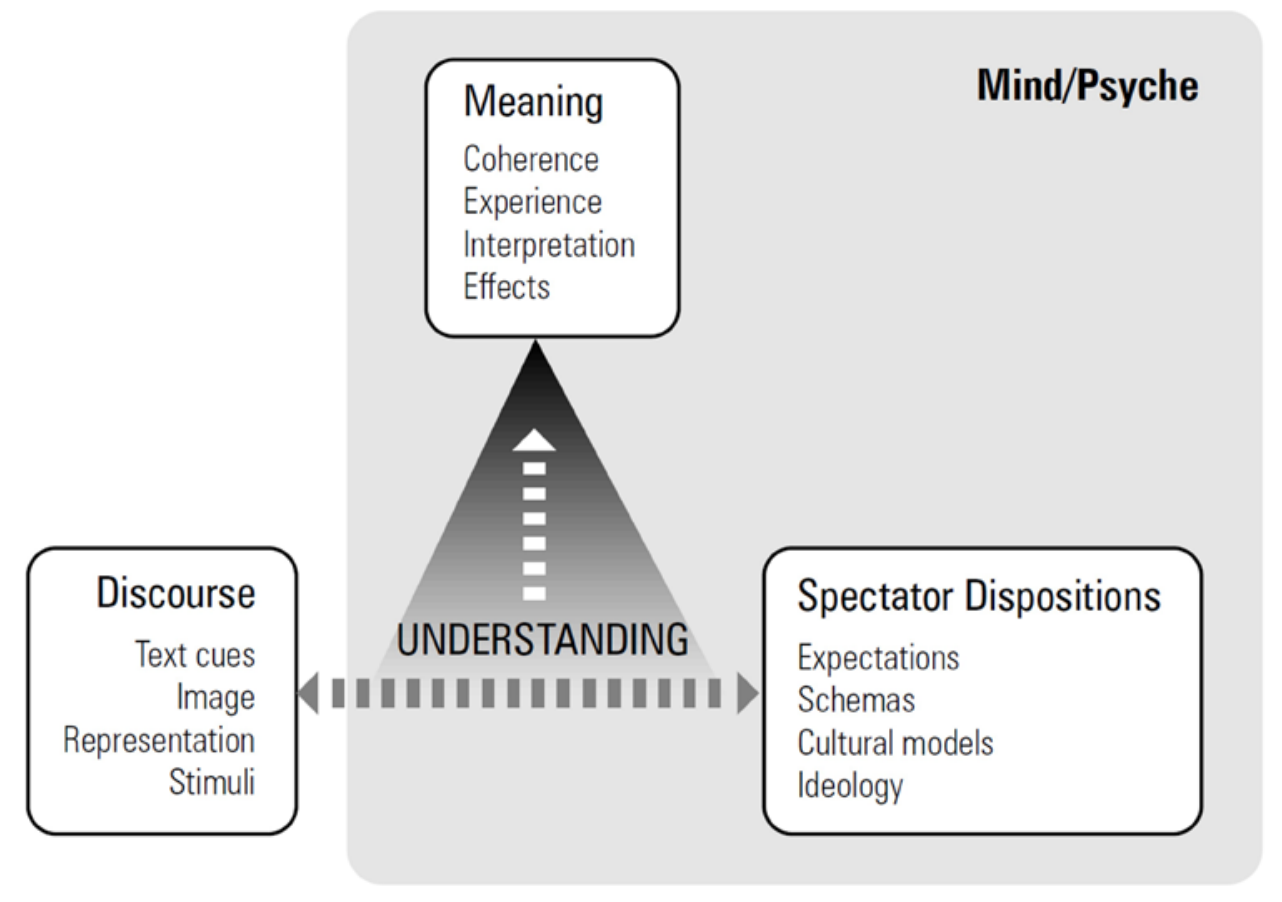

\section{Caption: “Persson's model of how meaning emerges from understanding. Diagram by}

Younhee Jung. Reprinted from Persson 2003: 24.

Transposing Persson’s model to documentary would incur several problems related to the previously mentioned critiques of cognitive approaches to film. First, the discourse would have to be linked to "everyday life," since it ultimately refers to real life rather than a fictional diegesis. Thus, the resulting “meaning” would have to be seen to reflect varying degrees of "real life" and have either a more direct or a more mediated relationship with reality. These linkages would be difficult to implement in this type of diagram, which establishes a universal schematic of film reception. Second, the model does not account for viewing contexts (e.g., institutional, sociocultural, historical, technological) that determine the authorial construction of the discourse as well as the generation of meaning in the 
spectator. Third, being a "reception” model (like most cognitive film models) it disregards the filmmaker (or institution) as a constitutive agent in constructing the discourse, shaping the meaning, and informing spectator dispositions. Moreover, by focusing on psychological structures, it also disregards the possible impact of films on behavior and social structuresan essential aspect of documentaries. Fourth, the model is clearly located within cognitive psychology, providing little scope for interdisciplinary theoretical modeling in relation to noncognitive paradigms (e.g., phenomenology, anthropology, psychoanalysis).

That is not to say that Persson's theory is not useful to documentary analyses. On the contrary, the multiple levels of meaning he derives from his model, and which he outlines in bottom-up and top-down configurations, contain essential insights applicable to documentary reception, such as the important distinction between sensorial perception and character engagement. However, for an emerging discourse that has yet to progress to the study of fiction film and that aims to foster interdisciplinary scholarship rather than predetermine or confine it to a particular discipline, a more flexible approach is required as a breeding ground for future models and research designs. Perhaps that is why the aforementioned scholars, Bondebjerg, Eitzen, and Plantinga, prefer to conceive loose and provisional guidelines and directions rather than comprehensive or deterministic models.

With this in mind, in lieu of a schematic spectatorship model we propose the use of a heuristic framework, with six areas of theoretical modeling, to study documentary (Figure 2). This not only integrates cognitive concepts on a theoretical level, but also informs the empirical investigation of film production and spectatorship through applied practice as manifested in audience research or the filmmaking process itself. Such a framework is supposed to provide scholars and practitioners with the conceptual tools they need to untangle questions related to the natural and social world, as well as affective and cognitive mechanisms, all of which frame the conventions and implications of documentary production and reception. 


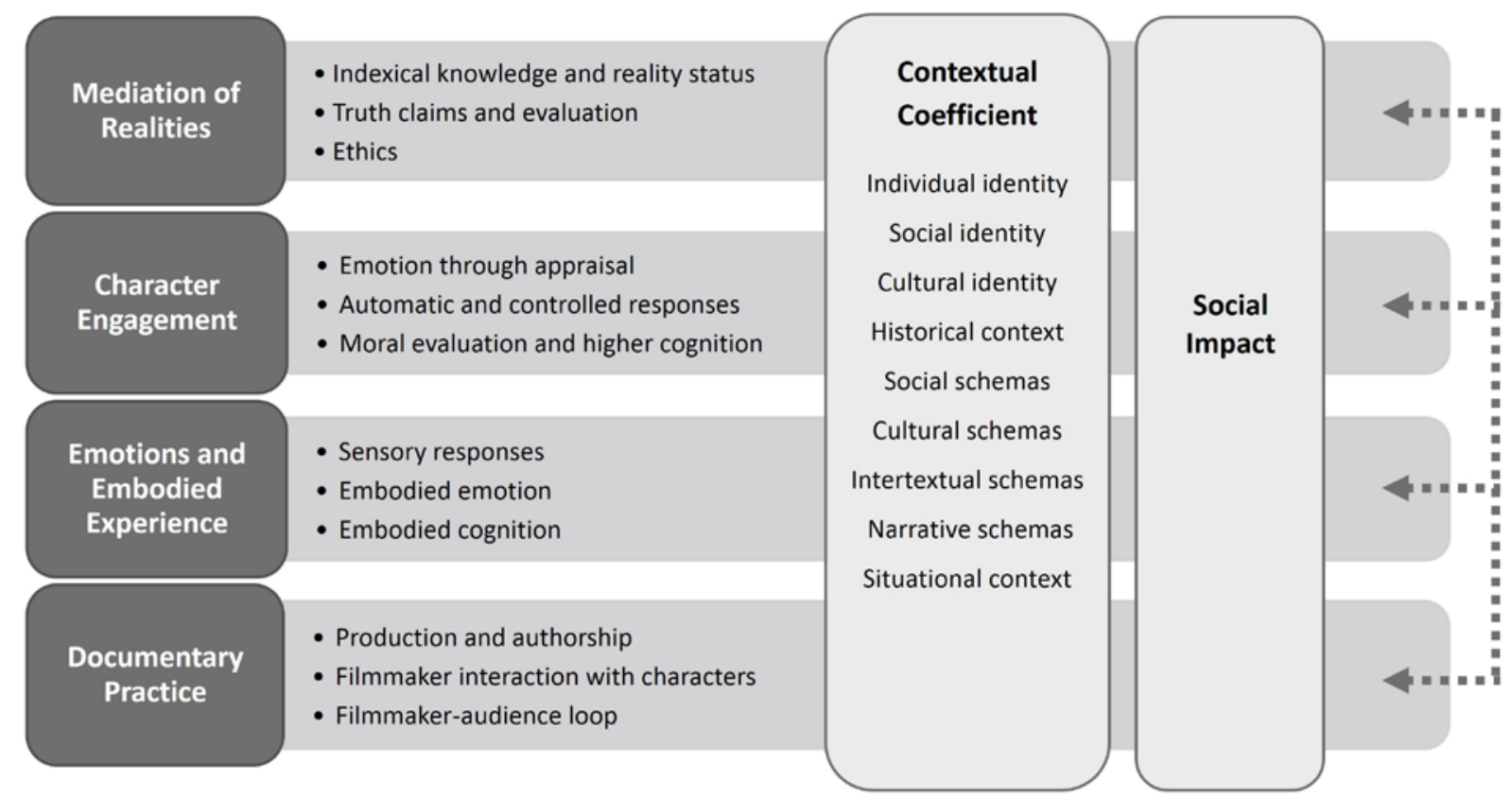

\section{Caption: "Four areas of interest and theoretical modeling.}

\section{Diagram by the authors.”}

It is important to reemphasize that this framework constitutes neither a model nor a taxonomy. A model would illustrate the process of documentary reception or the "life span" of a documentary (for example, authorial inspiration, research, production, exhibition, perception, and social impact). A taxonomy, on the other hand, would approach documentary by way of philosophically distinct topics (for example, epistemology, metaphysics, and axiology), different attributes (for example, textual features, interpretative strategies, and situational variables), or distinct discursive purposes (for example, conveying information, entertaining/engaging, changing minds/behaviors, and serving as a medium for social exchange). ${ }^{5}$ These are all valid approaches, and we hope that our framework provides an impetus for cognitive and noncognitive scholars to engage with documentary in a cognitivepragmatic way that enables the rigorous formulation of such models and taxonomies.

However, the reason why we hesitate to formulate such systematic categorizations, proposing instead a more fundamental and heuristic approach, is that it would be counterintuitive and limiting to privilege one system over another at this preliminary stage, 
especially for such a heterogeneous form and practice as documentary. Furthermore, a pragmatic approach does not warrant a long, cumbersome discourse about the most suitable system,but rather calls for a holistic and grounded perspective anchored in a particular research question relating to a concrete case study (whether this is a single film or a body of films that share similar attributes). Consequently, our framework is a combination of the possible models and taxonomies mentioned above. It represents an intuitive and heuristic rather than a systematic categorization, and it is based on our previous research, which includes theorization, empirical studies, and filmmaking practice, as well as the editing of our book Cognitive Theory and Documentary Film (Brylla and Kramer 2018).

The five modules in the above graphic are preliminary examples of different yet overlapping research focuses, suggesting possibilities for theory building, research, and analysis. Furthermore, in the spirit of pragmatism and interdisciplinarity, this framework is heterarchical and modular with multiple entry points, encouraging a grounded approach in which the specific case study and research context dictate which areas are used in what configuration as exemplified by the dotted arrows in the diagram. In the same vein, the listed items in each area are not exhaustive, and while they may reveal our position within a cognitive tradition we believe they provide enough scope for crossdisciplinarity. For instance, “character engagement” may invite the deployment of psychoanalytic models, while “emotions and embodied experience” may link well to affect theory.

This first area of interest, "Mediation of Realities," explores the complex relationship between represented and inferred reality as experienced and interpreted by the viewer, and addresses the perceived indexical relationship between audiovisual depictions and their real counterparts. This involves, for example, the evaluation of truth claims and ethical considerations, as well as the generation of emotions with implications in real life. The spectator's construction of reality is not only informed by the film text, but also by the way she frames the film according to her individual, social, cultural, and historical dispositions, as well as by her previous knowledge (cognitive schemas and scripts) of the topics and 
characters represented. These converging mediation processes can also be used to explore the viewer's evaluation of authorship, for example in documentaries that reflexively reveal the production process, or where the viewer has prior knowledge or an intertextual awareness of the filmmaker's modus operandi.

A key aspect in this area is the spectator's evaluation of a film's reality status by judging its relationship to reality and the difference between fiction and nonfiction (see Barratt 2007). For documentaries, this evaluation results in what degree of factuality is perceived (i.e., what does or does not correspond to occurrences and people in real life). This consideration is especially pertinent to documentaries that overtly merge fact and fiction, such as Jean Rouch’s ethnofiction film Me, a Black (1959), in which the characters act out selfscripted roles intermingled with their real, everyday lives. However, docudramas (or fiction films that claim to be based on real events) with a coherently scripted diegesis closely linked to historical events that are anchored in collective memory, such as the 9/11 film United 93 (Paul Greengrass, 2006), can also be subjected to reality-status checks, for example believing that certain elements are factual, accepting others as artistic license inherent to the dramatization process, or rejecting inaccuracies as either propaganda or oversights. The issue of dramatization also links to reenactments in documentaries that reflexively question the very notion of truth and knowledge acquisition, such as Errol Morris’s docudrama miniseries Wormwood (2017). Morris’s use of stylization and narrative ambiguity—iconically used in The Thin Blue Line (1988), the quintessential documentary homage to Akira Kurosawa’s Rashomon (1950)—prompts the viewer to experience the film's narrative as a constructed artifact, thereby raising ethical and epistemological questions about the director's own practice and documentary's mediation of reality in general.

The second area, “Character Engagement,” covers emotion generation through appraisal, automatic and controlled engagement responses, moral evaluation, and higher cognition in relation to screen characters and their situations. It focuses on the audience's engagement with screen characters, an area that has been of major interest to cognitive 
scholars such as Murray Smith and Carl Plantinga, albeit one that has predominantly centered on fiction films. Character engagement is related to the narrative orchestration and aesthetic attributes of the film text and to the fundamental question of whether the engagement happens on an empathetic or sympathetic level (M. Smith 1994). Further considerations include the evaluation of cross-gender and cross-demographic engagement, as well as crossspecies engagement with, for example, anthropomorphized animals. For documentary film in particular, the discussion needs to also consider two types of spectatorially inferred indexicality: the link between screen characters and real characters, as well as the one between authorship within and outside the text. Both may be informed by the audience's prior knowledge acquired through other films, other media, or personal experience.

A case in point is Jon Bang Carlsen’s documentary oeuvre. During his longitudinal film research, which he records on camera, Bang Carlsen often lives in the same environment he explores. In his earlier films, he used to write the dialogue he wanted his real-life characters to speak, but in later films he started directing fictional scenes (based on his quasiethnographic observations) enacted by amateur actors. Thus, what appears to be an observational documentary is in fact a "staged documentary,” a term Bang Carlsen repeatedly uses to describe his working method, which he has developed in films such as Hotel of the Stars (1981), Before the Guests Arrive (1984), and It's Now or Never (1996).

In terms of veridicality, Bang Carlsen’s films comprise a subjective reproduction of his experience of real places, characters, and situations. Despite directing what are technically docudramas, he does not frame the films as such. For instance, in the title sequence at the beginning of It's Now or Never (1996), it remains ambiguous as to whether the film is fiction or nonfiction, since the list of the characters' names bears no indication as to whether they are either (A) actors enacting a fictional script, (B) actors reenacting real events, (C) real people enacting a fictional script, (D) real people reenacting real events, or (E) real people "living” real events. From a viewer's perspective, all five scenarios are possible options, but the film's refusal to clearly index these fiction-nonfiction configurations complicates the viewer's 
general emotional and cognitive engagement. Ultimately, that engagement becomes dependent on a variety of factors, including knowledge of observational documentary conventions, awareness of Bang Carlsen’s modus operandi, acquired information from paratexts, viewing contexts (e.g., documentary festivals), and the critical assessment of documentary-fiction hybrid films. It is on this level of audience awareness that the line between documentary and fiction becomes blurred. However, fiction films in general use clearer forms of indexing (with beginning and end credits), whereas documentaries tend to be indexed more ambiguously.

One pertinent question is whether the viewer's indexing of veridicality through “reality-status evaluation” (see Grodal 2009) influences their empathy/sympathy and appraisal responses to the main character, Jimmy, and his search for a wife, which forms the film's main plotline. Thus, the level of character engagement depends largely on whether the audience is aware of the film's actual reality status and the corresponding real-life status of the screen characters, and is underscored by the way emotions are coordinated in different scenes in the film. Lower types of viewer empathy work automatically, regardless of realitystatus evaluation, since they are only dependent on direct, embodied perceptions of a target's emotional state, as well as on personal experience of similar emotional states as the target. On the other hand, higher empathetic states, such as role-taking, require more controlled and conscious cognitive assessment (Hoffman 2000), which in Bang Carlsen’s films “compete” with the reality-status evaluation processes, influencing the degree to which the viewer experiences full-scale empathy with the characters. Similarly, the appraisal process responsible for emotion generation has both automatic and controlled pathways, but it is not dependent on the matching of emotional states to produce vicarious emotional experiences (Wondra and Ellsworth 2015). Appraisal can be elicited by merely appraising narrative situations relevant to our own well-being, which happens in the case of Jimmy’s search for a mate- the longing for love is a universal emotion.

Consequently, whether or not viewers are aware of the characters' and the story’s 
actual reality status, they can still obtain a vicarious emotional experience with screen characters in Bang Carlsen’s films. Full empathetic engagement would possibly require a viewer who is not aware of these films' ambiguous status in relation to actuality or scripted events. In other words, such a viewer would consciously deem the films to beunambiguously_either fiction or documentary. A cognitive framework therefore enables the mapping of different routes toward character empathy in documentary based on the realitystatus evaluation elicited by the perceived degree of authorial mediation. This is also tied to the viewer's social and moral evaluation of the screen characters.

The third area, “Emotions and Embodied Experience,” addresses “online” or “moment-to-moment” processes in relation to somatic responses. Based on developments (especially the previously mentioned pragmatic turn) in the natural and social sciences, as well as in philosophy, this area adopts the 4EA-related paradigms that have informed such concepts as “enacted perception” (Noë 2004), “embodied cognition” (Shapiro 2011), and the “phenomenological mind” (Gallagher and Zahavi 2008). The metatheoretical aim of this area is twofold. First, it calls for an expansion of the disciplinary term cognitive to include sensory responses and low-level emotions, as well as related high-level cognitive processes, such as comprehension and interpretation. Second, this expansion inevitably requires a crossdisciplinary approach, highlighting the aforementioned intersection between the natural sciences and the humanities.

This area can address documentaries that stimulate sensory responses based on perceptual engagements with inanimate objects and spaces, such as the "slow TV" genre that originated in Norway and features very long camera takes of, for example, moving trains and migrating reindeer. In contrast to these non-character-driven films and overlapping with the previous area of “character engagement," certain character-driven documentaries that highlight onscreen embodied experiences may relegate indexical links to real-life referents to the background of audience reception and render the film text the primary referent for the characters. For instance, Brian Hill’s musical documentary Pornography: The Musical (2002) 
reflexively displays the artifice of letting real-life sex workers sing their stories (intermingled with conventional interviews), which renders the film an obviously performed, onscreen spectacle. In combination with a lack of a conventional plot structure (the film is an assemblage of disparate and self-contained vignettes), the spectator's engagement with the characters is situated within the text as momentary embodied experiences, reducing realitystatus checks in terms of factuality and the actual real-life characters. Such a bottom-up approach, however, also needs to take into account top-down processes and the difference in viewing contexts and audience groups. For instance, film scholars have praised the satirical performativity of Pornography: The Musical (e.g., Paget and Roscoe 2006), while critics have deemed it quasi-pornographic and exploitative (Baker 2006: 169).

The fourth area, "Documentary Practice,” is dedicated to revealing the actual construction process of documentary, highlighting the role of authorship. Despite the emergence of practice-based filmmaking research, there has been little attempt to embrace cognitive theory as a research paradigm for either fiction or documentary practice. Applied cognitive approaches have been limited to empirical studies using, for example, neurocognitive research and quantitative and qualitative accounts of viewing practices. But whereas such applications employ cognitive theory as a purely analytical tool, we advocate its use as a synthesizing tool for conceptualizing and producing documentary films. Interestingly, this creative application of cognitive theory in practice has been popular in performance and theater studies (e.g., May 2015) and creative writing (e.g., Skains 2016). There have also been isolated attempts to implement cognitive approaches in documentary film practice (e.g., Keeney 2016), film editing (Pearlman 2009) and ethnography (Pink 2009, 2012). Also, although not an example of its direct application, the Danish Broadcasting Corporation (DR/Danmarks Radio) has started using cognitive systems for gauging audience responses; the data is fed back to commissioning editors, who may then ask for production practices to be tweaked accordingly (Gregersen et al. 2017: 3).

Essentially, the focus here is on a quasi-reverse-engineering process that enables the 
filmmaker or practice-led researcher to create a hypothetical spectator that she or he can then use as a basis for production decisions about, among other things, narrative structure, cinematography, editing, and distribution. Therefore, from the perspective of scholarly research the area of film practice is prone to merge two nonfiction writing genres often perceived to be incompatible with one another: critical academic analysis and didactic textbook description. This merger allows the extrapolation of theoretical knowledge from empirical fieldwork and the exploration of how it informs the fieldwork. As a result, it has the potential to act as a bridge between the academy and the film industry; however, to do this it requires more flexible scholarly boundaries, allowing, for example, the use of anecdotal evidence. After all, as Sean Cubitt reminds us, the extreme specificity of anecdotal data "provides depth and color to the generalist findings of methods that deal with multiple instances and large-scale tendencies” (2013: 6), and grounds more abstract formations, such as representations, in specific instances. On a scholarly level, this area provides insight into the (intended) reception as well as the production of a film, thematizing the "filmmakeraudience loop” (Plantinga 2011), which establishes the documentary practitioner as an entity driven by similar affective and cognitive mechanisms as the spectator.

Nevertheless, this area does not only include practices where filmmakers or practiceled researchers deliberately use cognitive methods, it can also explore the filmmaker's profilmic or extratextual cognitive engagement with characters and situations, especially if this engagement is revealed to the spectator, for example through the filmmaker's onscreen interventions. The focus of a film can thus become placed on the creative process itself: the filmmaker's decisions as a result of affective and cognitive interactions with the real characters, as well as with the filmmaking apparatus. Czech Dream (Vít Klusák and Filip Remunda, 2004) embodies this scenario well: two filmmaking students document their own large-scale hoax advertising campaign for a fictional hypermarket. Using the latest insights into consumer behavior, they expose the media's powers of persuasion. Discussing the filmmakers’ practice inevitably relates to the area of analyzing character engagement in terms 
of a conventional goal-driven narrative, but also in terms of ethics. The viewer is forced to ethically evaluate the filmmakers' mission to fool hundreds of people as being either an exploitative practice or a revelatory, intrepid endeavor. Another example is the animated documentary Approved for Adoption (Laurent Boileau and Jung Henin, 2012), in which Korean codirector Jung Henin depicts the story of his life. Abandoned by his biological parents at the age of five, and subsequently adopted by a Belgian family, who took him from South Korea to Belgium, Jung cathartically processes the historical roots of his identity: his journey from abandoned and displaced child to successful Belgian cartoonist. The film uses Jung's own animated renditions of his childhood interspersed with short documentary scenes of him returning to Seoul as an adult. The result is a complex, performative diegesis, through which the spectator reflexively engages with Jung’s multiple screen characters: real child, animated child, reflective filmmaker, cartoonist, ethnic Korean, and cultural Belgian. The four main areas of the framework need to be extended by a so-called contextual coefficient, arguably the most critical element in the pragmatic pursuit of incorporating extratextual considerations into spectatorship analysis. Although some of the listed items in this area (which, again, are by no means exhaustive) are already embedded in the four research areas, the nature of documentary and the universalizing tendency of cognitive models warrant a special emphasis on contexts. It is a cue to the researcher that spectatorship is not universal, abstract, and fixed. This contextual coefficient is designed to frame either of the four areas with "real-life” determinants, such as individual, social, and cultural identity; history; social and cultural schemas; intertextual schemas; and the situational context of the actual film viewing. The latter becomes particularly important when considering documentary material as part of video installations in museums or galleries, where it operates through a more embodied audience interaction with the artifact but can also involve political agendas, such as John Akomfrah’s The Unfinished Conversation, a multiscreen installation currently exhibited at the Tate Modern, which explores Black identity in the United Kingdom. The medium, too, plays a crucial role, and new forms, such as transmedia, crossmedia, immersive media, virtual 
reality, and augmented reality have increasingly been used to create distinct embodied experiences of documentary films.

Finally, the "social impact” addresses the intended or unintended consequences of social interaction or behavior, which is linked to Eitzen’s (2007) “consequentiality” or “reallife implications” argument. For example, it is hardly surprising that most activist films are documentaries (or, at least, include artistic reenactments of real events, such as Amnesty International's 2008 Stuff of Life, a short film on the interrogation technique of waterboarding), because the assertion of factuality and the emphasis on the real-life, harmful consequences of taking no action provide greater motivation and scope for social action. But, even in non-activist documentaries social impact plays a crucial role, as it can relate to either the pro-filmic characters and their world, during or after production, or the local/global community as a result of the film’s dissemination to particular audiences (such as commissioning editors, festival audiences, NGO stakeholders, or anthropology students). Therefore, this research area relates to a variety of domains that employ nonfiction audiovisual means for particular social purposes, such as ethnography, activism, propaganda, promotion, and education. Kate Nash and John Corner (2016: 234-237) emphasize how emotional engagement is often a key strategy adopted by filmmakers who want to achieve a particular social impact, and this renders cognitive models highly relevant as tools for filmmaking practice. The development of "strategic impact documentaries” relies on the identification and address of target audiences (233), implying that the scholarly analysis of social impact has to be based on audience research or the conceptualization of specific audience demographics. In some instances, the social impact is so significant and global that international media reports and policy changes are easily traceable. This is the case with the activist documentary Blackfish (Gabriela Cowperthwaite, 2013), which arguably contributed to SeaWorld ending its orca breeding program and phasing out live performances using captive orcas in $2016 .^{7}$ 
still have social consequences, whether the audience is aware of them or not. For instance, the main character of To Be and to Have (Nicolas Philibert, 2002), teacher Georges Lopez, unsuccessfully sued the filmmakers, claiming that he, his pupils, and their parents had been misled into believing that the film would be used for small-scale educational purposes. Instead, it was an international theatrical and commercially successful release, which he claimed had adverse effects on his pupils. ${ }^{8}$ This is where the difference between the contextual coefficient and the social impact is crucial, as both may be closely related but not interchangeable. Another example is the use of social stereotypes-a common contextual coefficient in documentary production and reception. This particular coefficient may or may not lead to the social impact of prejudice toward and discrimination against certain communities in real life, a psychological and social consequence of stereotyping (Kite and Whitley 2016).

\section{Conclusion}

The four research elements of the framework outlined in this article (the mediation of realities, character engagement, emotion and embodied experience, and documentary practice), in conjunction with the contextual coefficient and social impact, have the potential to expand the scope for the intersection between documentary film and cognitive film theory. The short documentary examples demonstrate the overlapping nature of the proposed research areas while simultaneously highlighting the necessity of particular focuses of analysis. The framework also stresses the importance of bottom-up, as well as top-down, mechanisms for analyzing spectatorship, drawing attention to both the differences and similarities between documentary and fiction film. It should be seen as a proposal open to development, in that it points to fruitful areas of research and encourages a pragmatic perspective that is grounded and crossdisciplinary. In fact, the reason for presenting it is to broaden the scope for a more engaged and enduring cognitive-documentary discourse, and, as such, scholars are invited to adopt, adapt, refine, or debate this framework, whether in a cognitive or noncognitive research context. This is why it is malleable and expandable, and 
the four areas are indicative, merely suggesting possibilities for theory building, research, and analysis.

Catalin Brylla is Senior Lecturer in Film at the University of West London. Focusing on documentary film studies, cognitive film theory, phenomenology, and visual anthropology, his research aims for a pragmatic understanding of documentary spectatorship in relation to experience, empathy, and narrative comprehension. He has coedited, with Helen Hughes, Documentary and Disability (Palgrave Macmillan, 2017) and is currently writing a book on stereotypes and spectatorship in documentary film. As a practice-led researcher, he has made documentaries about blindness and women's football in Zanzibar. His films have been screened and broadcast internationally. Email: catalin.brylla@uwl.ac.uk

Mette Kramer is a Film Lecturer at the University of Copenhagen. She has written on emotion and cognitive film theory in a number of Danish and international film journals and anthologies. She is currently finishing a book project on attachment, cognition, and affect. Email: ram@hum.ku.dk

\section{References}

Austin, Thomas. 2007. Watching the World: Screen Documentary and Audiences.

Manchester, UK: Manchester University Press.

Baker, Maxine. 2006. Documentary in the Digital Age. Boston: Focal Press.

Barratt, Daniel. 2007. “Assessing the Reality-Status of Film: Fiction or Non-Fiction, Live Action or CGI?” In Narration and Spectatorship in Moving Images, ed. Joseph D. Anderson and Barbara Fisher Anderson, 62-79. Newcastle upon Tyne, UK: Cambridge Scholars Publishing.

Barratt, Daniel. 2014. “The Geography of Film Viewing: What Are the Implications of Cultural-Cognitive Differences for Cognitive Film Theory?” In Cognitive Media Theory, ed. Ted Nannicelli and Paul Taberham, 62-82. London: Routledge.

Bondebjerg, Ib. 1994. "Narratives of Reality: Documentary Film and Television in a 
Cognitive and Pragmatic Perspective.” Nordicom Review 1:65-87.

Bondebjerg, Ib. 2015. “The Embodied Mind: When Biology Meets Culture and Society.” Palgrave Communications 1 (n. 15015). doi:10.1057/palcomms.2015.15.

Bondebjerg, Ib. 2017. “The Creative Mind: Cognition, Society and Culture.” Palgrave Communications 3 (n. 19). doi:10.1057/s41599-017-0024-1.

Bordwell, David, and Noël Carroll, eds. 1996. Post-Theory: Reconstructing Film Studies. Madison: University of Wisconsin Press.

Brylla, Catalin, and Mette Kramer, eds. 2018. Cognitive Theory and Documentary Film. London: Palgrave Macmillan.

Carroll, Noël. 2003. Engaging the Moving Image. New Haven, CT: Yale University Press.

Chanan, Michael. 2010. “Going South: On Documentary as a Form of Cognitive Geography.” Cinema Journal 50 (1): 147-154.

Coëgnarts, Maarten, and Peter Kravanja. 2015. "With the Past in Front of the Character: Evidence for Spatial-Temporal Metaphors in Cinema.” Metaphor and Symbol 30 (3): 218-239.

Corner, John. 2000. “What Can We Say about Documentary?” Media, Culture and Society 22 (5): 681-688.

Corner, John. 2008. “Documentary Studies: Dimensions of Transition and Continuity.” In Rethinking Documentary: New Perspectives, New Practices, ed. Thomas Austin and Wilma DeJong, 13-28. Maidenhead, UK: Open University Press.

Cowie, Elizabeth. 2011. Recording Reality, Desiring the Real. Minneapolis: University of Minnesota Press.

Cubitt, Sean. 2013. “Anecdotal Evidence.” NECSUS: European Journal of Media Studies 2 (1): 5-18.

Currie, Gregory. 1999. "Visible Traces: Documentary and the Contents of Photographs.” Journal of Aesthetics and Art Criticism 57 (3): 285-297.Eitzen, Dirk. 1995. “When Is a 
Documentary? Documentary as a Mode of Reception."

Cinema Journal 35 (1): 81-102.

Eitzen, Dirk. 2007. “Documentary’s Peculiar Appeals.” In Moving Image Theory: Ecological Considerations, ed. Joseph D. Anderson and Barbara Fisher Anderson, 183-199. Carbondale: Southern Illinois University Press.

Gallagher, Shaun, and Dan Zahavi. 2008. The Phenomenological Mind: An Introduction to Philosophy of Mind and Cognitive Science. London: Routledge.

Gregersen, Andreas, Birger Langkjær, Lene Heiselberg, and Jacob Lyng Wieland. 2017. “Following the Viewers: Investigating Television Drama Engagement through Skin Conductance Measurements.” Poetics 64: 1-13. doi:10.1016/j.poetic.2017.06.002.

Grierson, John. 1966. Grierson on Documentary. Oakland: University of California Press.

Grodal, Torben Kragh. 2009. Embodied Visions: Evolution, Emotion, Culture, and Film. Oxford: Oxford University Press.

Hake, Sabine. 2012. Screen Nazis: Cinema, History, and Democracy. Madison: University of Wisconsin Press.

Hoffman, Martin L. 2000. Empathy and Moral Development: Implications for Caring and Justice. Cambridge: Cambridge University Press.

Johnson, Mark. 2006. “Cognitive Science.” In A Companion to Pragmatism, ed. John R. Shook and Joseph Margolis, 369-377. Malden, MA: Blackwell Publishing.

Keeney, Declan. 2016. “The Issue of Emotion in Stories of Conflict: Documentary Filmmaking in a Post Conflict Northern Ireland.” PhD diss., Queen’s University Belfast. http://ethos.bl.uk/OrderDetails.do?uin=uk.bl.ethos.706991.

Kite, Mary E., and Bernard E. Whitley. 2016. Psychology of Prejudice and Discrimination.

New York: Routledge. 
MacDougall, David. 1998. Transcultural Cinema. Princeton, NJ: Princeton University Press.

MacDougall, David. 2006. The Corporeal Image: Film, Ethnography, and the Senses. Princeton, NJ: Princeton University Press.

Madzia, Roman, and Matthias Jung, eds. 2016. Pragmatism and Embodied Cognitive Science: From Bodily Intersubjectivity to Symbolic Articulation. Berlin: De Gruyter.

May, Shaun. 2015. Rethinking Practice as Research and the Cognitive Turn. Basingstoke, UK: Palgrave Pivot.

Mills, C. Wright. 2000. Sociological Imagination. Oxford: Oxford University Press.

Nannicelli, Ted, and Paul Taberham, eds. 2014. Cognitive Media Theory. London: Routledge.

Nash, Kate, and John Corner. 2016. "Strategic Impact Documentary: Contexts of Production and Social Intervention.” European Journal of Communication 31 (3): 227-242. doi:10.1177/0267323116635831.

Nichols, Bill. 1991. Representing Reality: Issues and Concepts in Documentary. Bloomington: Indiana University Press.

Nichols, Bill. 1994. Blurred Boundaries: Questions of Meaning in Contemporary Culture. Bloomington: Indiana University Press.

Nichols, Bill. 2001. Introduction to Documentary. Bloomington: Indiana University Press.

Noë, Alva. 2004. Action in Perception. Cambridge, MA: MIT Press.

Odin, Roger. 1989. “A Semiopragmatic Approach of the Documentary.” In Image, Reality, Spectator: Essays on Documentary Film and Television, ed. Willem De Greef and Willem Hesling, 90-100. Leuven: Acco.

Paget, Derek, and Jane Roscoe. 2006. “Giving Voice: Performance and Authenticity in the Documentary Musical.” Jump Cut 48. http://www.ejumpcut.org/archive/jc48.2006/MusicalDocy/. 
Pearlman, Karen. 2009. Cutting Rhythms: Shaping the Film Edit. Boston: Routledge.

Persson, Per. 2003. Understanding Cinema: A Psychological Theory of Moving Imagery. Cambridge: Cambridge University Press.

Peterson, James. 1996. “Is a Cognitive Approach to the Avant-Garde Cinema Perverse?” In Post-Theory: Reconstructing Film Studies, ed. David Bordwell and Noël Carroll, 108-129. Madison: University of Wisconsin Press.

Pink, Sarah. 2009. Doing Sensory Ethnography. London: Sage.

Pink, Sarah. 2012. Situating Everyday Life. Los Angeles: Sage.

Piotrowska, Agnieszka. 2013. Psychoanalysis and Ethics in Documentary Film. Abingdon, UK: Routledge.

Plantinga, Carl. 1997. Rhetoric and Representation in Nonfiction Film. Cambridge: Cambridge University Press.

Plantinga, Carl. 2005. “What a Documentary Is, After All.” Journal of Aesthetics and Art Criticism 63 (2): 105-117.

Plantinga, Carl. 2009. “Spectatorship.” In The Routledge Companion to Philosophy and Film, ed. Paisley Livingston and Carl Plantinga, 249-259. New York: Routledge.

Plantinga, Carl. 2011. “Folk Psychology for Film Critics and Scholars.” Projections 5(2): $26-50$

Plantinga, Carl. 2013. “‘I’ll Believe It When I Trust the Source’: Documentary Images and Visual Evidence.” In The Documentary Film Book, ed. Brian Winston, 40-47. Basingstoke, UK: Palgrave Macmillan.

Plantinga, Carl, and Greg M. Smith, eds. 1999. Passionate Views: Film, Cognition, and Emotion. Baltimore, MD: Johns Hopkins University Press.

Ponech, Trevor. 1999. What Is Non-Fiction Cinema? Boulder, CO: Westview Press. 
Renov, Michael. 1993. “Toward a Poetics of Documentary.” In Theorizing Documentary, ed. Michael Renov, 12-36. New York: Routledge.

Renov, Michael. 2004. The Subject of Documentary. Minneapolis: University of Minnesota Press.

Richardson, Kay, and John Corner. 1986. "Reading Reception: Mediation and Transparency in Viewers’ Accounts of a TV Programme.” Media, Culture \& Society 8 (4): 485508. doi:10.1177/0163443786008004007.

Shapiro, Lawrence A. 2011. Embodied Cognition. New York: Routledge.

Shimamura, Arthur P., ed. 2013. Psychocinematics: Exploring Cognition at the Movies. New York: Oxford University Press.

Skains, Lyle. 2016. “Cognitive Approach.” In Creative Practice as Research: Discourse on Methodology. http://scalar.usc.edu/works/creative-practice-research/cognitiveapproach.

Smaill, Belinda. 2010. The Documentary: Politics, Emotion, Culture. New York: Palgrave Macmillan.

Smith, Greg M. 2007. “The Segmenting Spectator: Documentary Structure and The Aristocrats.” Projections 1 (2): 83-100.

Smith, Murray. 1994. "Altered States: Character and Emotional Response in the Cinema.” Cinema Journal 33 (4): 34-56.

Smith, Murray. 2017. Film, Art, and the Third Culture: A Naturalized Aesthetics of Film. Oxford: Oxford University Press.

Sobchack, Vivian. 2004. Carnal Thoughts: Embodiment and Moving Image Culture. Berkeley: University of California Press.

Tan, Ed S. 1996. Emotion and the Structure of Narrative Film: Film as an Emotion Machine. Mahwah, NJ: Routledge. 
Wang, Huiling. 2015. “Cognitive Science and the Pragmatist Tradition.” Phd diss., École normale supérieure de Lyon. https://tel.archives-ouvertes.fr/tel-01223306/document.

Ward, Paul. 2005. Documentary: The Margins of Reality. London: Columbia University Press.

William, Jennifer Marston. 2017. Cognitive Approaches to German Historical Film: Seeing Is Not Believing. New York: Palgrave Macmillan.

Winston, Brian. 2008. Claiming the Real: Documentary: Grierson and Beyond. London: British Film Institute.

Wondra, Joshua D., and Phoebe C. Ellsworth. 2015. “An Appraisal Theory of Empathy and Other Vicarious Emotional Experiences.” Psychological Review 122 (3): 411-428. doi:10.1037/a0039252. 


\section{Notes}

${ }^{1}$ This article considers the term documentary to encompass a wide range of audiovisual nonfiction genres and media, including obvious formats, such as documentary films, but also formats that may appear to be outside the reach of film scholarship, such as newscasts, commercials, and internet memes.

${ }^{2}$ Notable exceptions include the cultural contextualization of spatiotemporal perception (e.g., Barratt 2014; Coëgnarts and Kravanja 2015) and the cultural-historical contextualization of spectatorship (e.g., Hake 2012; William 2017).

${ }^{3}$ One of our major premises for the cognitive study of documentary is that humanities disciplines, such as visual arts and history, are equally as important as, and should be used in conjunction with, scientific disciplines.

${ }^{4}$ See Murray Smith’s Film, Art, and the Third Culture: A Naturalized Aesthetics of Film (2017) for an extensive application of Snow's idea of the "third culture" - the mediating agent between the cultures of the sciences and the humanities - to the aesthetics of (fiction) film and the other arts.

${ }^{5}$ Such taxonomies are indeed common in the rich field of documentary studies, though hardly any of those are based on cognitive principles. Two prominent examples include Bill Nichols’s $(1991,2001)$ previously mentioned six documentary modes that are based on form and spectatorial address, and Michael Renov’s (1993) four fundamental tendencies of documentary: to record/reveal/preserve, to persuade/promote, to analyze/interrogate, and to express.

${ }^{6}$ https://jonbangcarlsen.com/.

${ }^{7}$ https://www.bloomberg.com/news/articles/2016-03-17/urgent-seaworld-says-it-will-endkiller-whale-breeding-program.

${ }^{8}$ https://www.theguardian.com/world/2004/oct/03/film.france. 